\title{
Simulasi Penggunaan Intrusion Detection System (IDS) Sebagai Keamanan Jaringan dan Komputer
}

\author{
Barany Fachri*, Fadli Hamdi Harahap \\ Fakultas Sains Dan Teknologi, Program Studi Sistem Komputer, Universitas Pembangunan Panca Budi, Medan, Indonesia \\ Email: 1,"barany_fachri@dosen.pancabudi.ac.id, ${ }^{2}$ roymartinsbr180@gmail.com \\ Email Penulis Korespondensi: barany_fachri@dosen.pancabudi.ac.id
}

\begin{abstract}
Abstrak-Di era teknologi informasi saat ini, keamanan jaringan komputer merupakan bagian sebuah sistem yang sangat penting untuk menjaga validitas dan integritas data serta menjamin ketersediaan layanan pagi pengguna dari mana dan kapan saja. Dan disatu sisi manusia sudah sangat tergantung dengan sistem informasi. Hal itu menyebabkan statistik insiden keamanan jaringan terus meningkat tajam dari tahun ke tahun. Sehingga diperlukan suatu solusi untuk mengatasi hal ini, salah satunya adalah dengan simulasi. Simulasi dilakukan untuk menirukan sistem keamanan jaringan nyata yang ada dengan sifat yang lebih mudah untuk diamati daripada sistem aslinya, untuk mengetahui performansi sistem. Pada penelitian ini dibutuhkan sistem yang dapat menanggulangi ancaman yang mungkin terjadi secara optimal dalam waktu yang cepat, hal ini akan mempercepat proses penanggulangan gangguan serta pemulihan sistem atau layanan. Salah satu cara yang dapat digunakan untuk menanggulangi atau mengatasi hal tersebut adalah dengan menggunakan Intrusion Detection System (IDS). Salah satu aplikasi yang mendukung intrusion detection system (IDS) adalah Snort. Snort mampu melakukan analisis terhadap bentuk serangan intruder yang menyalahgunakan protokol jaringan.
\end{abstract}

Kata Kunci : Simulasi, Intrusion Detection System, Snort, Keamanan Jaringan dan Komputer.

Abstract-In the current era of information technology, computer network security is part of a system that is very important to maintain the validity and integrity of data and to ensure the availability of users' morning services from anywhere and anytime. And on one hand humans are very dependent on information systems. That causes the statistics of network security incidents to increase sharply from year to year. So we need a solution to overcome this, one of which is by simulation. Simulations are carried out to simulate existing real network security systems with properties that are easier to observe than the original system, to determine system performance. In this research, a system that is able to cope with threats that may occur optimally in a fast time is needed, this will speed up the process of handling disruptions and system or service recovery. One way that can be used to overcome or overcome this is to use the Intrusion Detection System (IDS). One application that supports intrusion detection system (IDS) is Snort. Snort is able to do an analysis of the forms of intruder attacks that misuse network protocols.

Keywords: Simulation, Intrusion Detection System, Snort, Network and Computer Security.

\section{PENDAHULUAN}

Keamanan jaringan komputer sangat dibutuhkan pada saat perkembangan teknologi komunikasi dan jaringan yang cukup pesat ini. Hal ini untuk menjaga validitas dan integritas data serta menjamin ketersediaan layanan bagi penggunanya. Sistem harus dilindungi dari berbagai serangan dan usaha-usaha penyusupan oleh pihak ketiga (attacker)[11].

Keamanan komputer adalah suatu cabang teknologi yang dikenal dengan keamanan informasi yang diterapkan pada komputer. Sasaran keamanan komputer antara lain adalah sebagai perlindungan informasi terhadap pencurian atau korupsi, atau pemeliharaan ketersediaan, seperti dijabarkan dalam kebijakan keamanan. Menurut Garfinkel dan spafford, ahli dalam komputer security, komputer dikatakan aman jika bisa diandalkan dan perangkat lunaknya bekerja sesuai dengan yang diharapkan[8].

Hal ini mengakibatkan semua komputer yang terhubung ke jaringan komputer sangat rentan terhadap serangan atau kegiatan yang bersifat merugikan yang dilakukan oleh orang lain yang bertujuan untuk mengambil data, memanipulasi data, bahkan merusak data-data berharga untuk tujuan tertentu.

Salah satu cara untuk mengamankan sebuah informasi yaitu dengan memasang teknologi firewall. Firewall akan melakukan sebuah kebijakan keamanan dengan memberikan aturan-aturan dijaringan tersebut untuk akses keluar masuknya paket data pada jaringan. Namun, keamanan yang dilakukan firewall biasanya dirancang hanya untuk memblokir trafik-trafik yang mencurigakan tanpa tahu mana trafik-trafik yang berbahaya dan mana trafik yang tidak berbahaya. Sehingga paket yang firewall rasa itu berbahaya akan ditindaki oleh firewall[2].

Oleh karena itu, dibutuhkan suatu sistem dalam menangani penyalahgunaan disebuah jaringan atau ancaman-ancaman dari penyusup yang akan terjadi yaitu dengan menggunakan aplikasi Intrusion Detection System (IDS) yaitu Snort dan WMware (Router OS) sebagai penindak lanjut terhadap alert Snort yang dihasilkan[3].

Ada beberapa penelitian terdahulu yang menggunakan metode Intrusion Detection System dalam mengamankan jaringan dan komputer . Salah satunya adalah penelitian [5] yang berjudul "Implementasi Ids (Intrusion Detection System) Pada Sistem Keamanan Jaringan Sman 1 Cikeusal”. Penelitian ini membahas Untuk mengetahui sebuah sistem Intrusion Detection System (IDS) snort dapat mendeteksi adanya serangan dan penyalah gunaan jaringan[1] . 


\section{METODE PENELITIAN}

\subsection{Tahapan Penelitian}

Berdasarkan analisis sistem keamanan yang ingin dibuat, maka tersusunlah tahapan-tahapan penelitian yang akan diusulkan antara lain dapat dilihat pada gambar berikut:



Gambar 1. Alur Tahapan Penelitian

Tahapan analisisnya sebagai berikut:

1. Mempersiapkan hardware dan software sebagai pendukung penggunaan Intrusion Detection System (IDS) sebagai keamanan jaringan komputer.

2. Merancang dan mengkonfigurasi Snort dengan mode IDS untuk sebagai keamanan jaringan computer.

3. Menguji sistem IDS dengan serangan-serangan seperti Nmap (Scanning Port) dan DOS (Denial Of Service).

4. Snort dengan mode IDS akan Menganalisa serangan-serangan tersebut di komputer server yang terpasang Snort.[12]

\subsection{Intrusion Detection System (IDS)}

Intrusion Detection System (IDS) adalah sebuah aplikasi perangkat lunak atau perangkat keras yang dapat mendeteksi aktivitas yang mencurigakan dalam sebuah sistem atau jaringan. IDS dapat melakukan inspeksi terhadap lalu lintas inbound dan outbound dalam sebuah sistem atau jaringan, melakukan analisis dan mencari bukti dari percobaan intrusi (penyusupan).[4]

Deteksi penyusupan (Intrusion Detection) adalah aktivitas untuk mendeteksi penyusupan secara cepat dengan menggunakan program khusus. Program yang digunakan untuk pendeteksian disebut sebagai IDS (Intrusion Detection System) . Tipe Dasar IDS adalah:

1. Rule-based systems, berdasarkan atas database dari tanda penyusupan atau serangan yang telah dikenal. Jika IDS mendeteksi Kemudian lintas sesuai dengan data dari database, maka pendeteksian tersebut langsung dikategorikan sebagai penyusupan.

2. Adaptive systems, sama seperti Rule-based tetapi ditambah dengan teknik lain yaitu membuka kemungkinan untuk mendeteksi metode penyusupan yang baru.

Selain tentunya melakukan pemindaian terhadap $\log$ sistem untuk memantau apakah terjadi kejadian yang tidak biasa. Dan skema jaringan yang akan dibuat seperti berikut:[4]



Gambar 2. Infrastuktur Jaringan IDS

Untuk penjelasan pada gambar di atas sebagai berikut :

a. Yang pertama yang harus dimulai dengan melakukan installasi Linux ubuntu 14.04.5 kemudian mengikuti alur installasi hingga selesai penginstallan. Saat telah selesai penginstallan lakukan penyesuaian IP Address dan konfigurasi pengroutingan.

b. Yang kedua Setelah selesai dalam penyetingan IP Address kemudian penginstallan paket-paket yang dibutuhkan dalam mendukung kinerja snort agar penginstallan Snort nanti tidak terjadi kesalahan dengan menginstall paket-paket yang di butuhkan berupa build-essential, libpcap-dev libpcre3-dev libdumbnet-dev, bison, flex, zlibblg-dev, liblzma-dev, openssl, libssl-dev.

c. Setelah semua paket di install kemudian tahap download dan install DAQ, SNORT, dan mengkonfigurasinya.

d. Bila semua tahap telah berhasil, lakukan tahap akhir yaitu pengujian sistem yang telah di bangun dan pengumpulkan data juga menganalisisnya.[10] 
JURNAL MEDIA INFORMATIKA BUDIDARMA

Volume 4, Nomor 2, April 2020, Page 413-420

ISSN 2614-5278 (media cetak), ISSN 2548-8368 (media online)

Available Online at https://ejurnal.stmik-budidarma.ac.id/index.php/mib

DOI 10.30865/mib.v4i2.2037

\section{HASIL DAN PEMBAHASAN}

\subsection{Instalasi}

Agar IDS berjalan dengan menggunakan Snort maka dibutuhkan paket-paket yang dibutuhkan agar penginstallan IDS tidak mendapatkan kesalahan nantinya dalam melakukan penginsatallan memerlukan perintah dalam linux yaitu:[6]

\#apt-get install

\# apt-get install -y build-essential libpcap-dev libpcre3-dev libdumbnet-dev bison flex zlibblg-dev liblzma-dev openssl libssldev.

\subsection{Penginstallan DAQ, Snort}

Setelah diinstall paket-paket yang mendukung dalam berjalannya pembangunan IDS dan kemudian menginstall tools tambahan agar Snort agar Snort dapat bekerja dengan maksimal dan handal dengan cara sebagai berikut:

a. Penginstallan $D A Q$

DAQ berfungsi sebagai pengaktif semua fitur inline yang ada pada Snort dan juga dengan semula Snort hanya mendeteksi akan tetapi dengan $D A Q$ ini Snort dapat mencegah penyerangan dengan cara menjalankan Snort pada mode inline menggunakan $D A Q$. Sebelum melakukan installasi pastikan dahulu mengunduh $D A Q$ dengan menggunakan wget seperti berikut:[5]



b. Penginstallan Snort

Setelah $D A Q$ di install lalu kemudian lakukan hal yang sama pada installasi Snort seperti berikut :

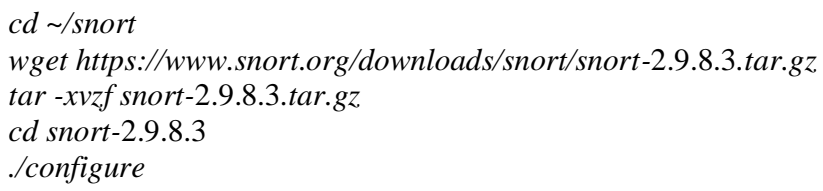

Setelah selesai semuanya instal nmap dan hping3 di client agar client bisa memberikan atau menyerang server.

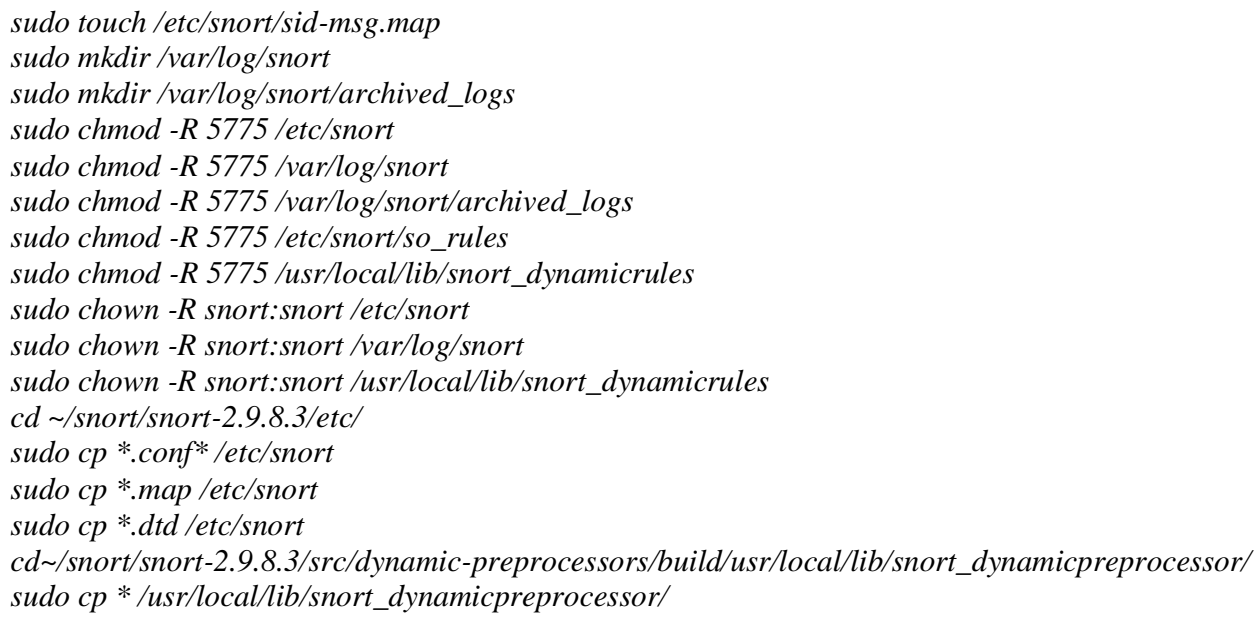

\subsection{Pengujian Jaringan}

Pada pengujian akhir komputer Sebelum melakukan pemasangan Snort pada sebuah komputer, yang pertama adalah melihat IP dari server, dari client, dan jika sudah terkoneksi dengan IP tersebut barulah memasang Snort dikomputer tersebut. sistem Snort akan dipasang dikomputer dan dicoba dengan percobaan memberikan serangan-serangan dan akan menampilkan alert sesuai ancamannya dan menampilkan penyalahgunaan jaringan yang terdeteksi.[1] 
JURNAL MEDIA INFORMATIKA BUDIDARMA

Volume 4, Nomor 2, April 2020, Page 413-420

ISSN 2614-5278 (media cetak), ISSN 2548-8368 (media online)

Available Online at https://ejurnal.stmik-budidarma.ac.id/index.php/mib DOI 10.30865/mib.v4i2.2037

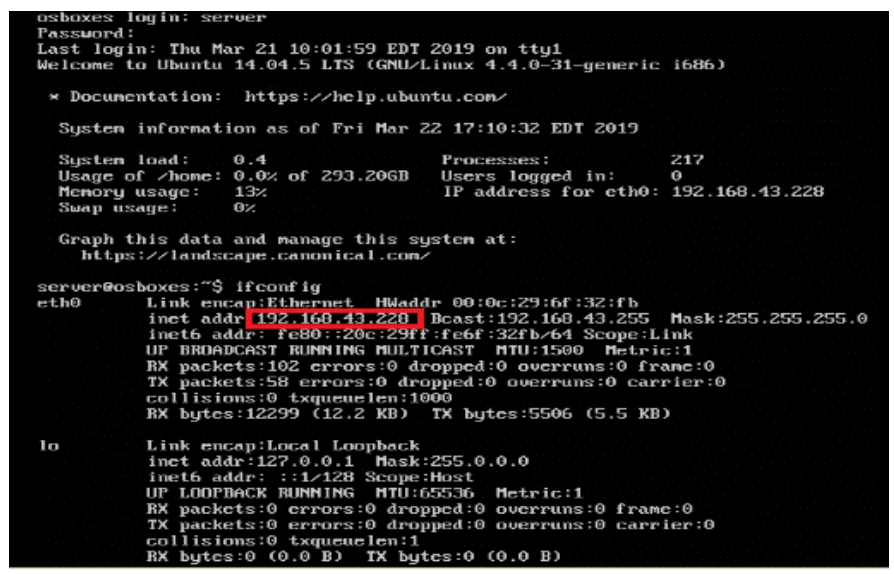

Gambar 3. Pengecekkan IP Server

Gambar 3 menunjukkan ketika penulis mengetikan ifconfig maka menampilkan IP 192.168.43.228 (sebagai Server) yang nanti akan diserang oleh client.[7]

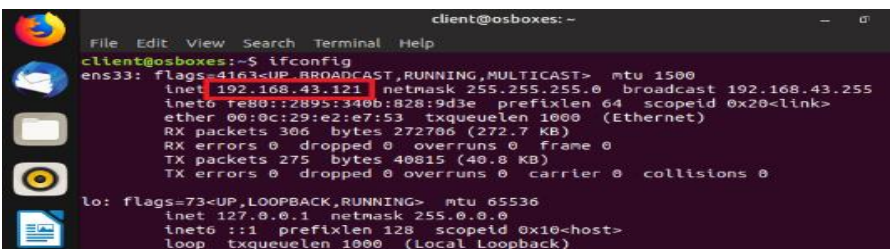

Gambar 4. Pengecekkan IP Client (Ubuntu)

Gambar 4 menunjukkan ketika penulis mengetikan ifconfig IP 192.168.43.121 (sebagai client di Ubuntu) yang nanti akan menyerang IP 192.168.43.228 (sebagai server).

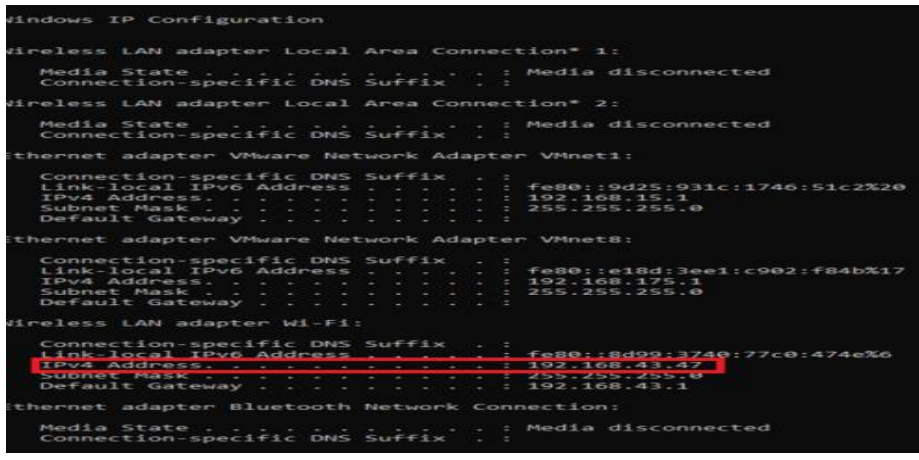

Gambar 5. Pengecekkan IP Client (windows)

Gambar 5 menunjukkan ketika penulis mengetikan ipconfig IP 192.168.43.47 (sebagai client di windows) yang nanti akan menyerang juga ke IP 192.168.43.228 (sebagai server).

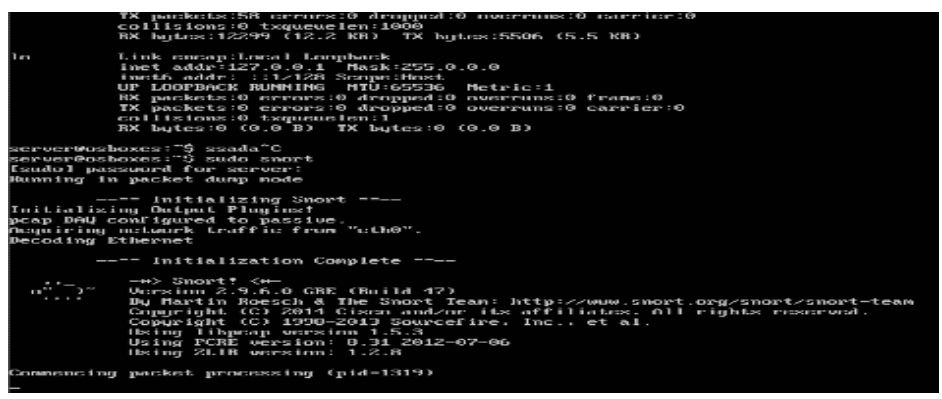

Gambar 6. SNORT

Pada gambar 6 menunjukkan ketika penulis mengetikan Sudo Snort cara kerja sebuah Snort dengan mode IDS. Setiap ada jaringan di lingkup IP server, maka Snort akan berjalan dengan real-time. 
JURNAL MEDIA INFORMATIKA BUDIDARMA

Volume 4, Nomor 2, April 2020, Page 413-420

ISSN 2614-5278 (media cetak), ISSN 2548-8368 (media online)

Available Online at https://ejurnal.stmik-budidarma.ac.id/index.php/mib

DOI 10.30865/mib.v4i2.2037

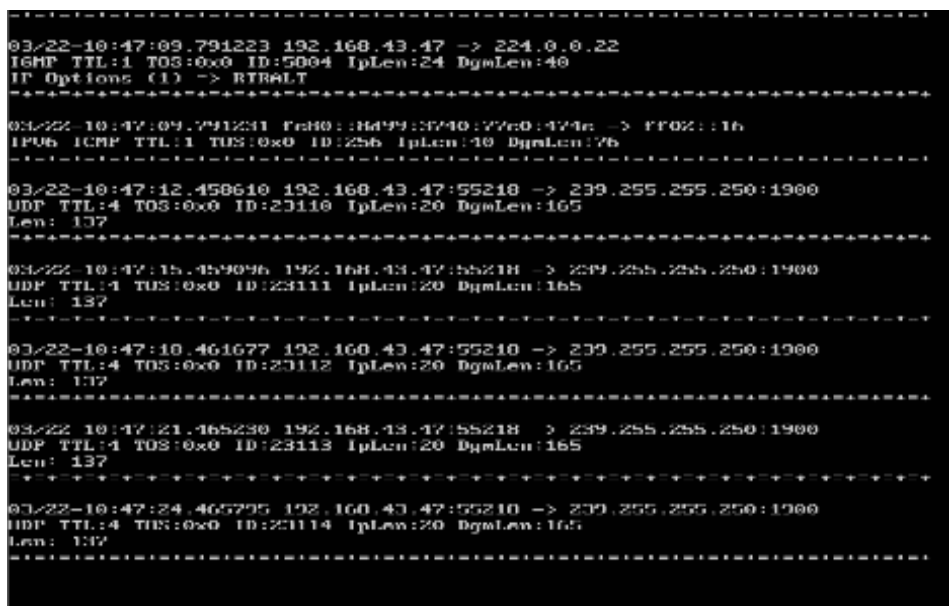

Gambar 7. Snort Dengan Mode IDS Telah Terpasang di Server dan Berjalan Secara Realtime

Gambar 7 menunjukkan Snort berhasil berjalan di server, setiap ada jaringan yang masuk ke IP server maka Snort akan berjalan secara real-time dan Snort akan mendeteksi paket-paket dari sebuah jaringan internet selama jaringat internet itu terkoneksi ke server dan dapat dilihat waktu Snort itu mendeteksi pada bulan 3 tanggal 20 pada waktu 10:50.[8]

\subsection{Tahapan Pengujian}

\section{Nmap (Port Scan)}

Komputer yang terpasang Snort akan dicoba dengan metode penyerangan nmap yaitu serangan dengan scanning port dari komputer penyerang (client). Hasil yang terjadi pada saat komputer diserang (Server) sebagai berikut:

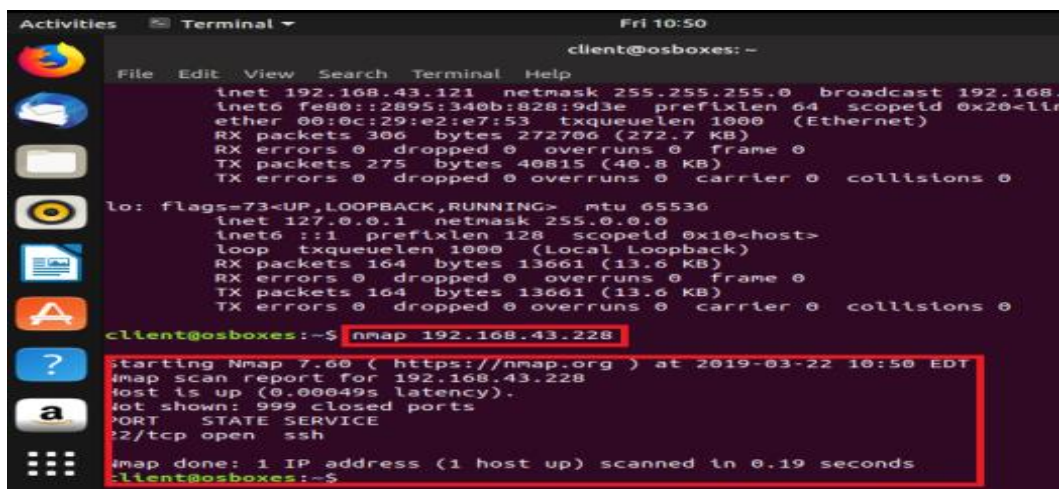

Gambar 8. Serangan Nmap (Port Scan)

Gambar 8 menunjukkan di client penulis menyerang dengan Nmap pada IP Server 192.168. 43.228 (server) dengan perintah Nmap 192.168.43.228 dan Nmap berhasil me-scanning port dari Server yaitu port 22 (Port SSH) dan dapat dilihat waktu saat penyerang me-scanning tahun 2019 bulan 3 dan tanggal 20, waktu serangan 11:07.

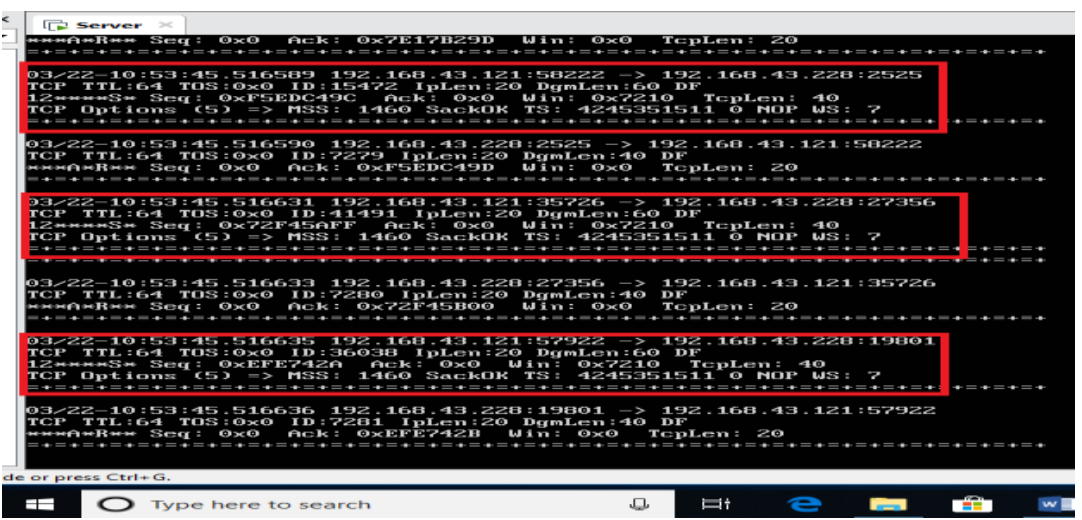

Gambar 9. Snort Dengan Mode IDS Menganalisis Serangan Nmap (Port Scan) 
JURNAL MEDIA INFORMATIKA BUDIDARMA

Volume 4, Nomor 2, April 2020, Page 413-420

ISSN 2614-5278 (media cetak), ISSN 2548-8368 (media online)

Available Online at https://ejurnal.stmik-budidarma.ac.id/index.php/mib

DOI 10.30865/mib.v4i2.2037

Gambar 9 menunjukkan IDS mendeteksi dan menganalisis IP 192.168.43.121 (komputer penyerang) pada bulan 3 tanggal 22 jam 10:53 menit melakukan scanning port terhadap IP 192.168.43.228 (komputer server/komputer yang terpasang Snort).

\section{DOS (Denial Of Service)}

Komputer yang terpasang Snort akan dicoba dengan metode penyerangan dengan serangan DOS dari komputer penyerang (client). Hasil yang terjadi pada saat komputer diserang (Server) sebagai berikut:

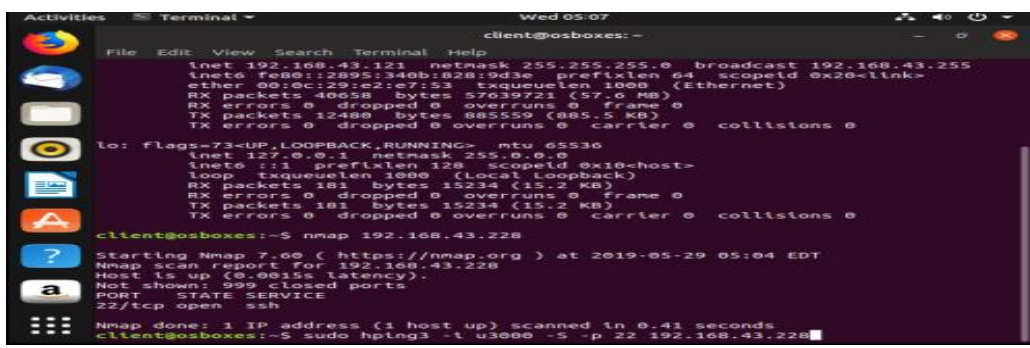

Gambar 10. Perintah Untuk Serangan DOS (Denial Of Service)

Gambar 10 menunjukkan di Client penulis mengetik perintah sudo hpimg3 -i u3000 -S -p 22 192.168.43.228 untuk menyerang server dengan serangan DOS.

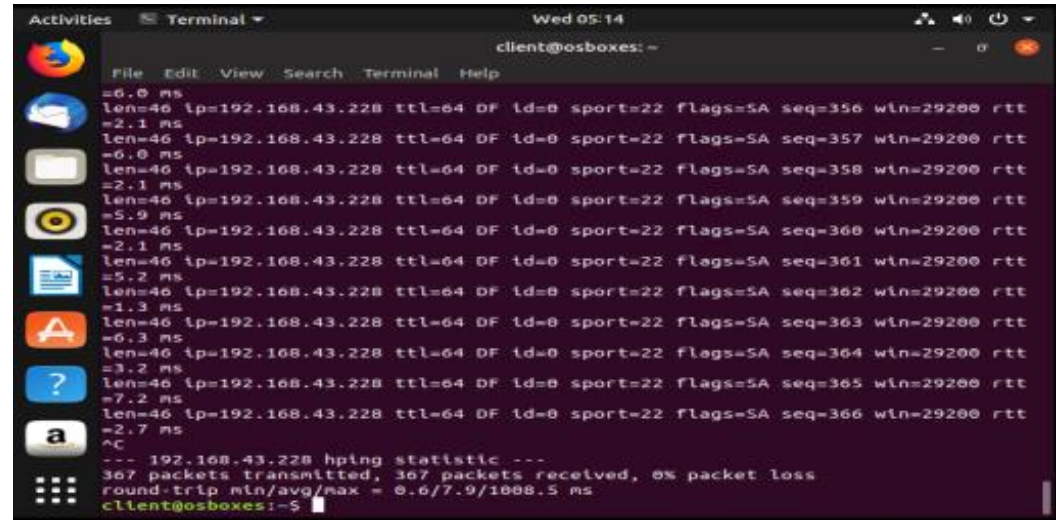

Gambar 11. Proses Client (Ubuntu) Me-request DOS Secara Terus Menerus Kepada Server (Ubuntu)

Gambar 11 menunjukkan client menyerang IP Server 192.168.43.228 dengan cara membanjiri jaringan dengan banyak data len=46 ip=192.168.43.228 $\mathrm{ttl}=64 \mathrm{DF} \mathrm{id}=50142$ sport=22 flags=RA seq=2427 win=0 $\mathrm{rtt}=3.8 \mathrm{~ms}$ sebanyak-banyaknya kepada jaringan server. Dan ketika penulis memberhentikan serangan DOS nya, dapat dilihat di client Ubuntu nya memberikan keterangan bahwa ada 367 paket yang di transmisikan kepada server, kemudian ada 367 paket yang di received (diterima) kepada si server, dan 0\% paket yang loss.

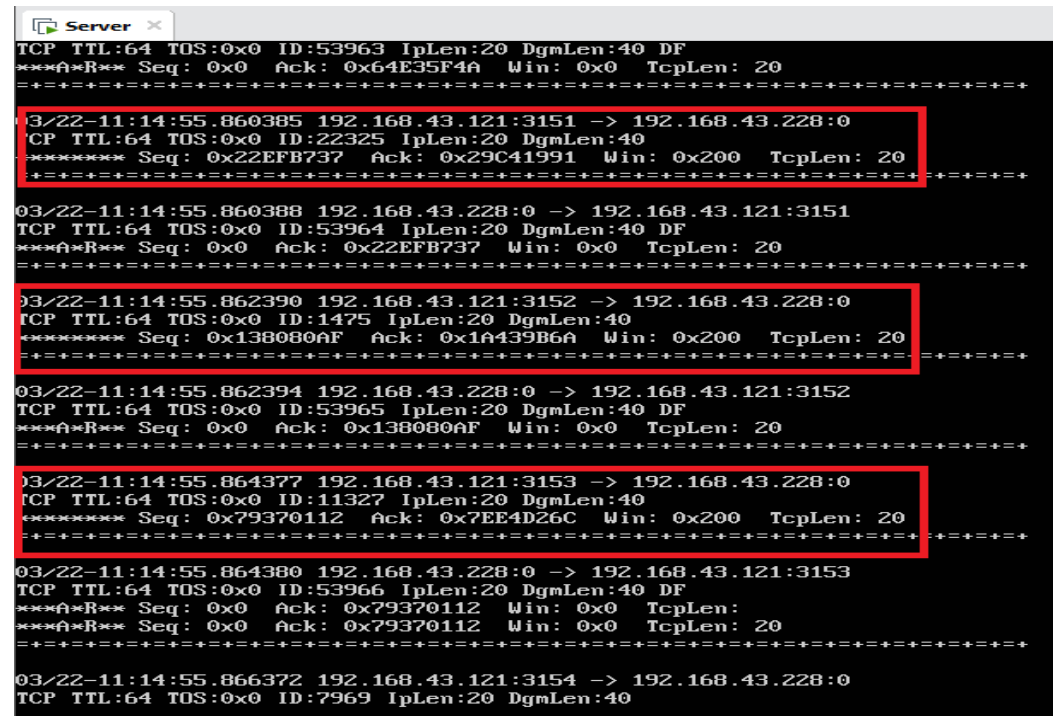

Gambar 12. Snort Dengan Mode IDS Mendeteksi dan Menganalisis Serangan DOS 
JURNAL MEDIA INFORMATIKA BUDIDARMA

Volume 4, Nomor 2, April 2020, Page 413-420

ISSN 2614-5278 (media cetak), ISSN 2548-8368 (media online)

Available Online at https://ejurnal.stmik-budidarma.ac.id/index.php/mib

DOI 10.30865/mib.v4i2.2037

Gambar 12 menunjukkan IP 192.168.43.121 (komputer penyerang) melakukan serangan DOS terhadap IP 192.168.43.228 (komputer server/komputer yang terpasang snort) dan dianalisis dengan Snort sebagai IDS di komputer (server) pada bulan 3 tanggal 22 dan pada jam 11.44.

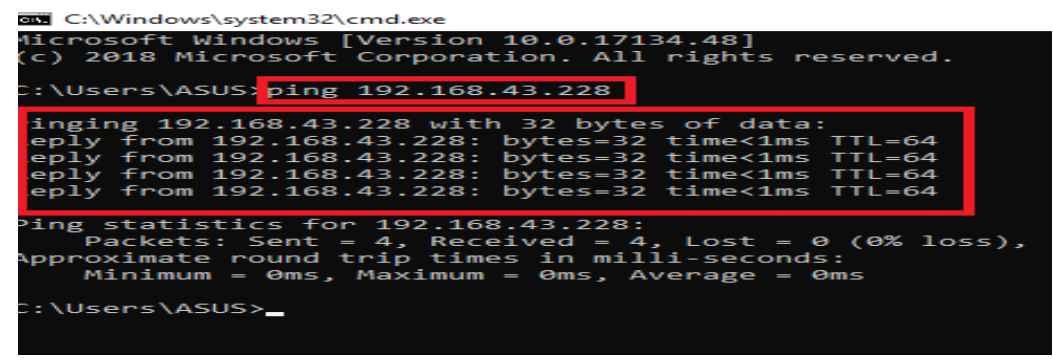

Gambar 13. Client (Windows) Nge-ping Server (Ubuntu)

Gambar 13 menunjukkan Client dari Windows mencoba menge-ping server IP 192.168.43.228 (komputer server) apakah Client dari Windows terkoneksi atau tidak dengan hasil reply from 192.168.43.228: bytes=32 times $<1 \mathrm{~ms}$ TTL $=64$

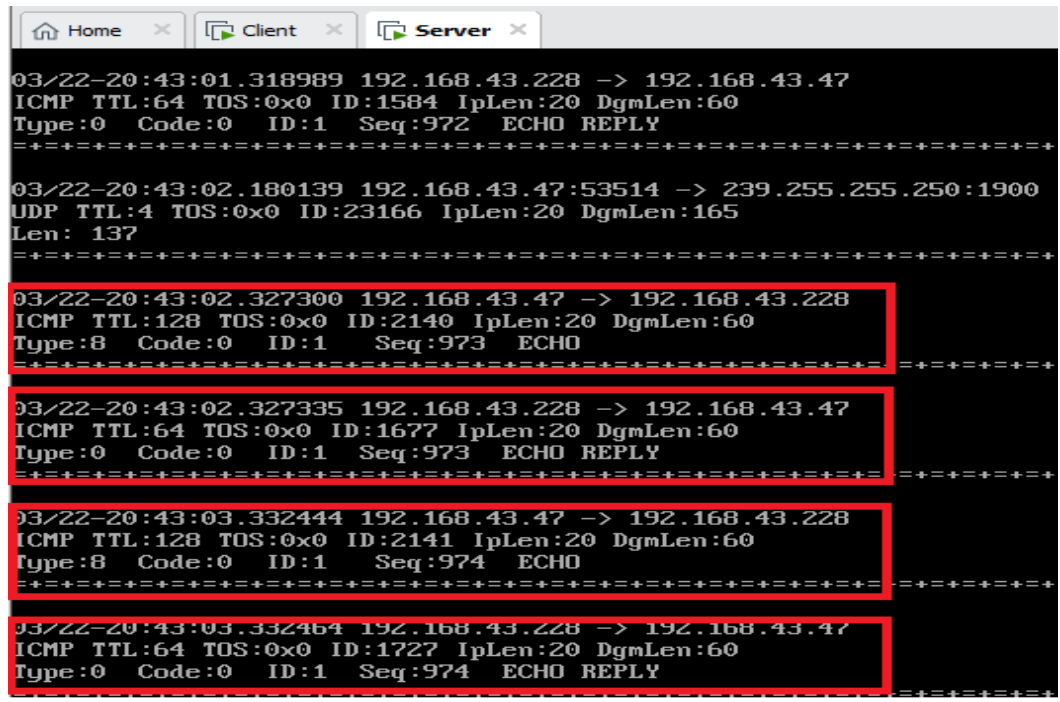

Gambar 14. Snort Dengan Mode IDS Mendeteksi dan Menganalisis Ping dari Client (Windows)

Gambar 14 menunjukkan Client dari Windows mencoba menge-ping server IP 192.168.43.228 (komputer server) dan dideteksi aktivitas dari Client (Windows) dengaan IDS yang terpasang di Server pada bulan 3 tanggal 22 pada jam 20:43.

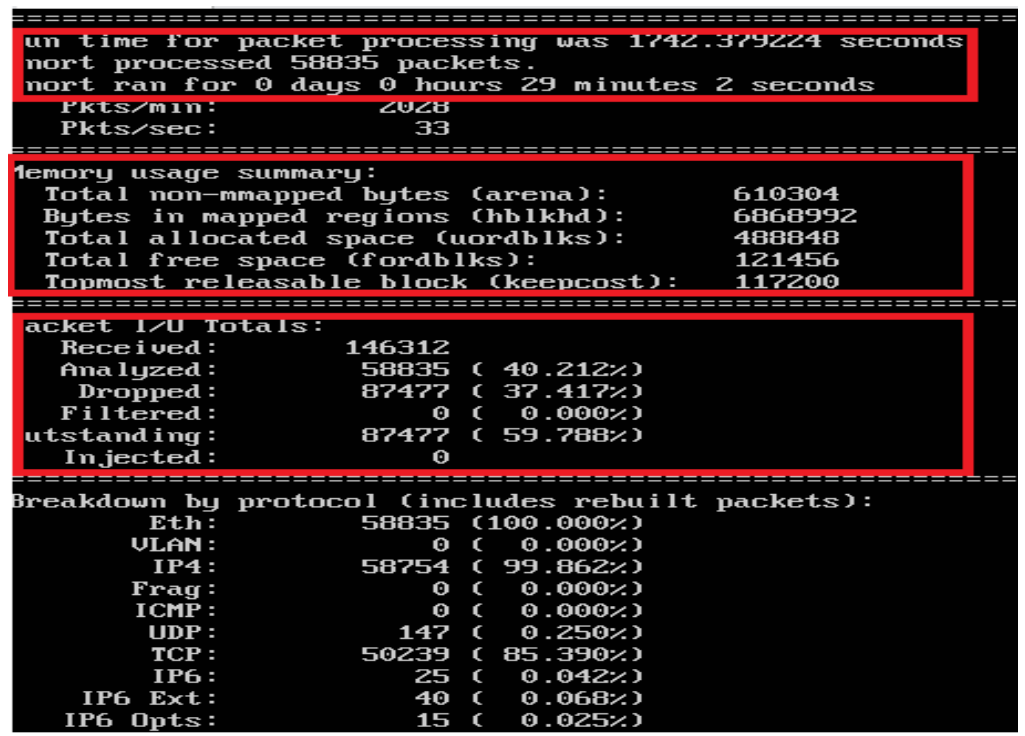

Gambar 15. Snort Dengan Mode IDS (Server) Menganalisis Seluruh Hasil Serangan. 
Pada gambar 15 menunjukkan juga merupakan hasil analisis dari Snort dan dapat dilihat dari gambar bahwa runtime untuk proses packet adalah 1742.379224 second dan snort memproses total packet 58835 packet. Dan juga dapat diketahui snort berjalan dalam waktu 29 menit 2 detik. memory sebesar 610.304 bytes. Dan dapat dilihat juga paket I/O Totals ada 146312 paket yang diterima dan yang dianalisis oleh IDS nya 58835 paket $(40.212 \%)$. Informasi yang dari packet log yaitu merupakan bahwa investigasi forensik dari sebuah jaringan. Dan juga informasi tersebut administrator sebuah jaringan dapat mengetahui apa-apa saja yang terjadi pada jaringan tersebut sehingga dapat menelusuri data serangan. Pada file Log yang bersaal dari Snort IDS menjadi bukti kejadian yang terjadi pada sebuah jaringan[9].

\section{KESIMPULAN}

Berdasarkan penelitian yang telah dilakukan, maka dapat diambil beberapa kesimpulan mengenai sistem pendeteksian dan pencegahan penyusup pada jaringan komputer menggunakan Snort yaitu:

1. Pemilihan penggunaan Intrusion Detection System sebagai keamanan jaringan komputer sangat tepat untuk diterapkan untuk mendeteksi sebuah serangan atau penyalahgunaan pada sebuah jaringan komputer dan menjaga integritas data dan informasi.

2. Pada komputer yang tidak terpasang Snort, maka komputer tersebut tidak dapat mengetahui apa-apa saja yang terjadi pada komputernya seperti ada aktivitas serangan maupun penyalagunaan sebuah jaringan.

3. Intrusion Detection System bersifat pasif, maksudnya sistem ini hanya dapat mendeteksi jika ada serangan ataupun penyalahgunaan jaringan komputer.

4. Pada saat menyerang server menggunakan DOS (Denial Of Service) paket yang dibawa tidak menjadi acuan/batas serangan ke server tersebut. Jadi untuk membatasi serangan terhadap server tergantung waktu saat memberhentikan serangan pada client tersebut.

\section{REFERENCES}

[1] Ertie Nur Hartiwati, "Keamanan Jaringan Dan Keamanan Sistem Komputer Yang Mempengaruhi Kualitas Pelayanan Warnet," J. Ilm. Inform. Komput. Univ. Gunadarma, pp. 27-33, 2014.

[2] E. K. Dewi, “Analisis Log Snort Menggunakan Network Forensic," JIPI (Jurnal Ilm. Penelit. dan Pembelajaran Inform., vol. 2, no. 2, pp. 72-79, 2017, doi: 10.29100/jipi.v2i2.370.

[3] E. Risyad, M. Data, and E. S. Pramukantoro, "Perbandingan Performa Intrusion Detection System ( IDS ) Snort Dan Suricata Dalam Mendeteksi Serangan TCP SYN Flood," J. Pengemb. Teknol. Inf. dan Ilmu Komput., vol. 2, no. 9, pp. 2615-2624, 2018.

[4] M. Mesran, R. Rusiana, and M. Sianturi, "Decision Support System for Termination of Employment using Elimination and Choice Translation Reality Method," J. Teknol. dan Sist. Komput., vol. 6, no. 4, p. 135, 2018, doi: 10.14710/jtsiskom.6.4.2018.135-138.

[5] Sutarti, P. Pancaro, Adi, and I. Saputra, Fembi, "Implementasi IDS (Intrusion Detection System) Pada Sistem Keamanan Jaringan SMAN 1 Cikeusal,” J. PROSISKO, vol. 5, no. 1, 2018.

[6] Suhartono, "Sistem Pengamanan Jaringan Admin Server Dengan Metode Intrusion Detection System ( Ids ) Snort," J. Sci. Pinisi, vol. 3, no. April, pp. 60-64, 2017.

[7] A. Lubis and A. Tarigan, "Security Assessment of Web ApplicationThrough Penetration System Techniques," Jend. Gatot Subroto Km, vol. 4, no. 100, pp. 296-303, 2017.

[8] I. Anugrah and R. H. Rahmanto, "Sistem Keamanan Jaringan Local Area Network Menggunakan Teknik DeMilitarized Zone," PIKSEL Penelit. Ilmu Komput. Sist. Embed. Log., vol. 5, no. 2, pp. 91-106, 2018, doi: 10.33558/piksel.v5i2.271.

[9] A. Essra, U. P. Budi, and M. T. Informatika, "Implementasi Ant-Based Routing Algorithm Pada Mobile Ad Hoc Network ( Manet )," vol. 2, no. 1, pp. 15-23, 2017.

[10] R. N. Fuad and N. W. Haikal, "Aplikasi Keamanan File Audio Wav ( Waveform ) Dengan," J. Nas. Inform. dan Teknol. Jar., vol. 1, no. 2, pp. 113-119, 2017.

[11] Supiyandi and D. Kurnia, "Perancangan VLAN pada Jaringan Lokal Web Server LKP Karya Prima Menggunakan Ubuntu Server," Peranc. VLAN pada Jar. Lokal Web Serv. LKP Karya Prima Menggunakan Ubuntu Serv., vol. 1, no. x, pp. 78-83, 2019.

[12] B. Fachri, "Perancangan Sistem Informasi Iklan Produk Halal Mui Berbasis Mobile Web Menggunakan Multimedia Interaktif," Jurasik (Jurnal Ris. Sist. Inf. dan Tek. Inform., vol. 3, no. 3, p. 98, 2018, doi: 10.30645/jurasik.v3i0.69. 